\title{
Bombay phenotype Oh blood group: two case reports. Acute puerperal uterine inversion and term pregnancy in labour
}

\author{
Pratibha Devabhaktuni*, Malati Ponnuru, \\ Vijaya Reddy Kalattoor, Nirupama Palakodeti
}

Department of Obstetrics and Gynaecology, Modern Government Maternity Hospital, Osmania Medical College, Hyderabad, Telangana, India

Received: 06 June 2021

Revised: 20 June 2021

Accepted: 21 June 2021

\section{*Correspondence:}

Dr. Pratibha Devabhaktuni,

E-mail:dpdnk@yahoo.com

Copyright: (C) the author(s), publisher and licensee Medip Academy. This is an open-access article distributed under the terms of the Creative Commons Attribution Non-Commercial License, which permits unrestricted non-commercial use, distribution, and reproduction in any medium, provided the original work is properly cited.

\begin{abstract}
Mrs. A, 30 years, para 3 with three live children was an unbooked emergency admission on 6 April 2007 with history of severe postpartum haemorrhage (PPH). She was in a state of shock with hypotension, tachycardia, pallor due to anaemia. Examination revealed the uterine inversion, uterus visible as a fleshy red mass protruded outside the vaginal introitus. Puerperal uterine inversion was reduced by vaginal manual reposition under observation through a mini laparotomy incision. She was transfused 4 units of O positive blood. On the second postoperative day she had signs and symptoms of a haemolytic transfusion reaction (HTR). She developed jaundice, haematuria and worsening anaemia. She was later detected to be Bombay Oh phenotype. Total 6 units of Bombay phenotype blood was transfused in a couple of days. Case 2: Mrs. R, 22 years primigravida, term gestation was admitted in labour in Government maternity hospital/Osmania medical college, Hyderabad on 26 July 2007. A resident from Mahaboob Nagar district of Andhra Pradesh, unbooked emergency admission in labour, had severe anaemia with 4 gms Hb\%. Her blood group was diagnosed as Bombay phenotype. She was given a vaginal delivery and transfused with compatible Oh Bombay blood obtained from Red Cross, Warangal, Andhra Pradesh.
\end{abstract}

Keywords: Bombay phenotype, Oh blood, Uterine inversion, PPH

\section{INTRODUCTION}

The salient features of Bombay blood group are the absence of $\mathrm{A}, \mathrm{B}$ and $\mathrm{H}$ antigens on red blood cells (RBCs) and presence of anti-A, anti-B and anti-H in serum. Since the antibodies in plasma react with all $\mathrm{ABO}$ phenotypes, these individuals can receive blood only of the Bombay blood type..$^{1,2}$

The Bombay blood group also known as $\mathrm{h} / \mathrm{h}$ or $\mathrm{Oh}$ is an extremely rare blood type, first reported in Bombay by Bhende et al in 1952..$^{1}$ The frequency of occurrence in India is about $1 / 10,000$ and in Europe about $1 / 1,000,000{ }^{2}$
The $\mathrm{H}$ antigen is the precursor to both the $\mathrm{A}$ and $\mathrm{B}$ glycoproteins that constitute group A and B blood types, respectively. Those with group $\mathrm{O}$ blood type have an absence of A or B glycoprotein but still have the $\mathrm{H}$ antigen. People with Bombay blood type have naturally occurring anti-A, anti-B and anti-H antibodies.

The mutational analysis has revealed that a person of the Bombay blood group carries homozygous recessive (hh) genotype instead of homozygous dominant $(\mathrm{HH})$ or heterozygous $(\mathrm{Hh})$ genotype of $\mathrm{ABO}$ blood group. So $\mathrm{H}$ antigen is not expressed on the RBC surfaces. The $h$ allele is a result of mutation of the $\mathrm{H}$ gene (FUT1) that expresses $\mathrm{H}$ antigen on RBC's of ABO blood group. Bombay 
phenotypes are homozygous (hh) for T725G mutation (leucine is changed to arginine) in the FUT1 coding region with gene deletion of FUT2. The consequence of this mutation is production of an inactivated enzyme that is incapable of producing $\mathrm{H}$ antigen. ${ }^{3,4}$ To label and diagnose a case as typical Bombay phenotype certain specialized tests like absorption-elution studies, titration of naturally occurring antibodies at different temperatures, inhibition of anti-H by $\mathrm{O}$ saliva secretor and secretor status should be performed as described by Bhatia 1974..$^{5,6}$

The clinical relevance of the Bombay or the Oh phenotype lies in the ability to cause haemolytic disease of the foetus and the newborn (HDFN) with its attendant consequences as the antibodies cross the placenta into the foetal circulation. ${ }^{7-9}$ In the case with Bombay phenotype, the pregnancy was reported to be uneventful and regular foetal-maternal monitoring with early detection of intrauterine anaemia was done with biweekly middle cerebral artery Doppler ultrasounds. ${ }^{10}$ This would be required as evidence of intrauterine anaemia will always necessitate foetal medicine referral and intrauterine transfusion. ${ }^{10}$

Also, if a caesarean section is required, intraoperative cell salvage may be of pivotal and lifesaving importance, especially if Bombay blood availability is delayed or unavailable. ${ }^{11}$ It may also be needed for exchange blood transfusion for neonates with haemolytic disease..$^{8,12,13}$

Arrangements for anti-H blood should be made throughout pregnancy in order to minimise the rare consequences of blood transfusion reactions and HDFN. Autologous blood donation and freezing within the pregnancy period will be instrumental, as the blood may be needed in critical emergencies.

Autologous blood donation during pregnancy is not as commonly done as in the non-pregnant since it can in itself lead to maternal and fetal complications like exaggeration of anemia in the mother, vasovagal symptoms and fetal heart rate abnormalities. Several studies have shown autologous blood storage during pregnancy to be relatively safe for both mother and fetus and to be feasible transfusion practice. ${ }^{14}$ An elderly gravida with the Bombay blood group who had a pregnancy complicated by diabetes, placenta previa and transverse lie following an in vitro fertilization was managed with autologous blood transfusion which was performed for the first time in a pregnant lady in their institute has been reported from Nepal. ${ }^{15}$ They reported that for the case they were able to collect $700 \mathrm{ml}$ of blood through two donations as patient presented late at 35 weeks. ${ }^{15}$

Others however proposed the need for reappraisal in obstetric patients. ${ }^{16}$ Yamada et al performed autologous blood donation and storage in 32 patients with placenta previa with almost no complications. They recommend starting blood collection at 32 week gestation with phlebotomy of $400 \mathrm{ml}$ per week so that a total of 1200$1500 \mathrm{ml}$ of blood can be collected and stored. ${ }^{17}$

\section{CASE REPORT}

\section{Case 1}

This woman was admitted in Government Maternity Hospital (GMH), Nayapul/Ameen Bagh, now known as Modern GMH, (MGMH, Petlaburz) on 6 April 2007. Mrs. A, 30 years, an unbooked emergency admission from Chandrayanagutta area of Hyderabad.

She was admitted with history of severe PPH, a para 3 with three live children. She was in a state of shock with hypotension, tachycardia, pallor due to anaemia. Examination revealed the uterine inversion, uterus visible as a fleshy red mass protruded outside the vaginal introitus with red oozing surface.

She was resuscitated and was given four units of $\mathrm{O}$ positive blood. Under anaesthesia manual reposition of the uterus was done by the Johnsons method. While the uterus was being reposited manually vaginally by pushing the uterus slowly cephalad through persistent pressure, first trying to push the part of the uterus close to the cervix. Through a mini laparotomy incision, the uterus was observed for its integrity, so that a perforation of the uterus would not occur, and also, we could guide the vaginal operator to exert pressure in the direction desired (Figure 1).

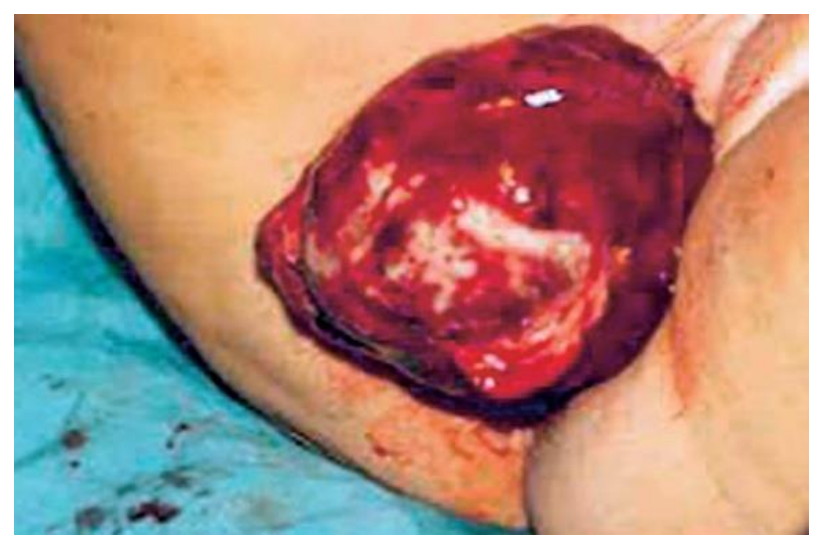

Figure 1: Acute puerperal complete uterine inversion in a woman with Bombay phenotype blood group; MGMH-2007.

Although Johnsons method of uterine reposition has been described under minilaparotomy observation, has been our improvisation to increase the safety and provide guidance to exercise pressure in the optimal direction which gives the vaginal operator greater confidence and a sense of security to be guided by the abdominal observer. This double set up we found it to be safer.

Now we thought that we have successfully managed the condition. 
On the second postoperative day she had signs and symtoms of a HTR. She developed jaundice, haematuria and worsening anaemia.

On day 3 of her admission, she was found to be having Bombay phenotype. This identification that she had Bombay phenotype was not an easy task. Due to HTR, her haemoglobin levels dropped to $3 \mathrm{gm}$. We were trying to crossmatch $\mathrm{O}$ positive blood but were not able to. That particular day, we had 10 units of $\mathrm{O}$ positive blood in our hospital. Some were reserved for other women awaiting surgery. Due to our request, the blood bank officer tried to cross match with all available units of blood in our blood bank. But of no avail. This process continued for two hours.

Next, we tried from the Institute of Preventive Medicine, (IPM), Red cross, Chiranjeevi blood bank in Jubilee Hills and Care hospital, Nampally sent cross matching samples to all these places. Trying to find out if suitable blood could be obtained. All through nearly four doctors trying to find out the information.

You can imagine the distances that have to be covered in Hyderabad traffic between 10 am to $2 \mathrm{pm}$. Also the difficulty in getting the phone connection. We were worried if she would go into irreversible shock. Around 2 pm, the doctor from Care hospital, Nampally, blood bank officer called and informed that it could be Bombay phenotype, which she confirmed after some time.

We found out that it was not available anywhere in Hyderabad. It had to be airlifted from Bombay. The addresses of possible donors and siblings were all collected and contacted for blood donation. Our hospital being an obstetrics and gynaecology speciality hospital, we did not have an in house intensivist and other specialists as she had transfusion reaction.

A decision was made to shift the patient to a multispeciality hospital, where ICU facilities, intensivists would be available. Dr. Dasari Prasada Rao, then Director of Nizams institute of medical sciences was contacted and the woman was transferred there till blood was airlifted from Mumbai and two units were transfused on the same day later. She received some more from some donors traced and contacted. Total 6 units of Bombay phenotype blood was transfused in a couple of days.

She survived. We could not recognize her a month later when she met us, she was beautiful looking.

\section{Case 2}

Mrs. R, 22 years primigravida, term gestation was admitted in labour in Government Maternity Hospital/Osmania medical college, Hyderabad on 26 July 2007.
A resident from Mahaboob Nagar district of Andhra Pradesh presented with labour pains, near term. She had irregular antenatal check-up in a village primary health centre, PHC. It was an unbooked emergency admission in labour. Investigations revealed that she had severe anaemia with 4 gms $\mathrm{Hb} \%$. Her blood group was diagnosed as the rare Bombay phenotype.

Labour monitoring and fetal monitoring were performed as per protocol. She had a vaginal delivery of a live baby, measured to minimize blood loss after delivery were duly followed. Good perineal support, slow delivery of the trunk, gentle traction on the cord, with cephalad counter traction on the uterus, allowing complete expulsion of the placenta and membranes without breaking the continuity of the membranes, occurring in an unhurried sequence, have reduced the blood loss.

After herculean efforts, we could obtain Bombay Oh blood and she was transfused with compatible Oh Bombay blood obtained from Red Cross, Warangal, Andhra Pradesh (Figure 2).

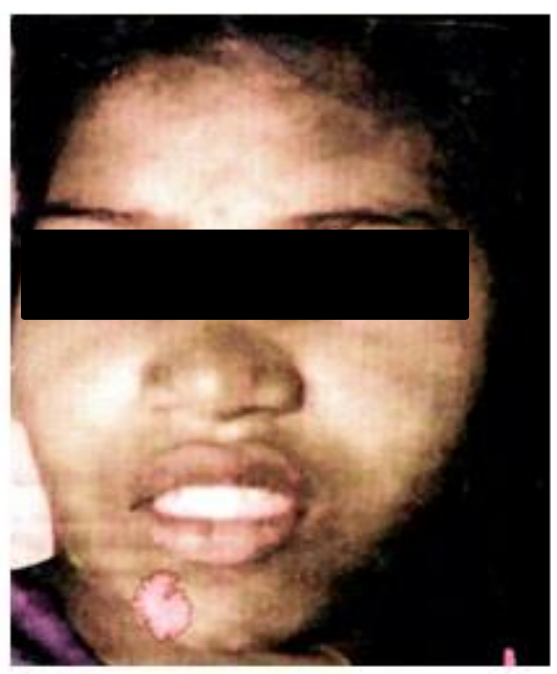

Figure 2: Term pregnancy admitted in labour emergency admission from Mahaboob Nagar.

Every pregnant woman must be screened for this rare phenotype during antenatal profile using anti-H sera in routine grouping, to avoid catastrophy. Rare blood group file is maintained by Red Cross organization.

\section{DISCUSSION}

The $\mathrm{H}$ antigen is synthesized by $(1,2)$-fucosyl transferases encoded by two distinct but closely linked genes, FUT1 and FUT 2. H antigen expression on red cells is dependent on FUT1 (the H gene). The FUT2 gene (secretor gene) is responsible for the formation of the $\mathrm{H}$ antigen in secretions (salivary glands) and gastrointestinal/genitourinary tissues. Bombay and para-Bombay phenotypes arise due to the homozygous inheritance of non-functional FUT1 
genes (hh allele). The two entities are distinguished by the presence or absence of the FUT2/secretor gene.

Bombay phenotype individuals are red cell $\mathrm{H}$ deficient non-secretors (hh, se/se), while para-Bombay individuals are redcell $\mathrm{H}$-deficient secretors (hh, $\mathrm{Se} / \mathrm{Se}$ or $\mathrm{Se} / \mathrm{se}) .{ }^{18}$

When compared to the Bombay phenotype, the paraBombay phenotype is more infrequent, occurring in a ratio of $1: 15 .{ }^{19}$ The incidence of the para-Bombay phenotype in the Chinese population has been documented to be $1: 12,000 .^{20}$ Para-Bombay individuals should be transfused with Bombay or para-Bombay blood if allo-anti-H or anti$\mathrm{HI}$ in their serum is clinically significant. In addition, this rare phenotype demands attention with respect to solid organ transplantation. Since the secretor gene is active in these individuals, salivary glands, gastrointestinal and genitor urinary tissues would still express ABH antigens despite the antigens being absent on red cells (Table 1 and 2).

Detection of Bombay blood group requires proper blood grouping and cross matching of the blood samples. This group would be categorized as the $\mathrm{O}$ group as it does not show any reaction to anti-A and anti-B antibodies just like normal $\mathrm{O}$ group. When cross matching with $\mathrm{O}$ group is done, then it would show cross reactivity or incompatibility. Therefore reverse grouping or serum grouping has to be done to detect this group.

Table 1: Mode of inheritance-Hh blood group.

\begin{tabular}{|lll|}
\hline Mother & Father & Off spring \\
\hline Hh & Hh & hh/HH \\
\hline hh & Hh & hh/Hh \\
\hline Hh & hh & hh/Hh \\
\hline
\end{tabular}

Table 2: Differences between Bombay and para-Bombay phenotypes.

\begin{tabular}{|ll|}
\hline Bombay phenotype & Para-Bombay phenotype \\
\hline Red cell H deficient & Red cell H-deficient \\
\hline Non-secretors & Secretors \\
\hline hh, se/se & hh, Se/Se or Se/se \\
\hline Non-functional FUT1 genes (hh allele) & Non-functional FUT1 genes (hh allele) \\
\hline FUT2 gene (secretor gene) absent & FUT2 gene (Secretor gene) Present \\
\hline
\end{tabular}

The incidence of Bombay phenotype is high in those states of India where consanguinous marriages are more prevalent, that is, Andhra Pradesh, Karnataka, Tamil Nadu, Maharashtra, Gujarat than the other states in India. Outside India, it is mostly confined to the South-East Asian countries. ${ }^{21}$

Out of the 179 cases reported by Sathe et al (1988) from the institute of immunohematology (formerly blood group reference centre, Bombay), 112 cases (62.6\%) cases belonged to Maharashtra. ${ }^{22}$

An acute hemolytic transfusion reaction may be the first manifestation that may lead us to detect the woman with the Bombay blood group phenotype, who are often misdiagnosed as the $\mathrm{O}$ blood group in cell typing. Acute hemolysis may result in disseminated intravascular coagulation or acute kidney injury, in patients who might have received large portions of mismatched blood before manifestations of hemolytic reactions.

Blood grouping, cross-matching, reverse grouping or plasma grouping would be mandatory for the selection of compatible blood before blood transfusion. On crossmatching, if multiple units of $\mathrm{O}$ positive blood group are detected to be incompatible, the indirect Coomb's test would detect the presence of incomplete antibodies. Lack of agglutination with anti-H antisera would confirm the diagnosis of the Bombay blood group.

As the Bombay blood group is a rare blood group, it is desirable to develop cryopreservation facilities for rare blood donor units. Every blood bank should maintain a rare blood type donor file.

Deo et al reported a case of a primigravida of Sri Lankan origin with the Bombay blood group diagnosed during antenatal evaluation. ${ }^{8}$ Saradabai and Sujatha reported a 28 year old primigravida at 28 weeks with antepartum hemorrhage due to major placenta previa. She was transfused one unit of blood donated by her maternal uncle with the Bombay blood group and two more units from the blood bank. ${ }^{23}$

Bullock et al describe two case reports of high-titer anti-H in pregnancy in $\mathrm{O}_{h}$ individuals. Of the case reports described, neither were affected by HDFN due to anti-H. Antibody titers were reported high in both cases (immunoglobulin $\mathrm{G}$ titer scores, 512 and 4000, respectively) and would be expected to cause some degree of HDFN, a surprising finding. Regular mean cerebral artery Doppler ultrasound was normal. High-titer anti-H in $\mathrm{O}_{\mathrm{h}}$ pregnancies may, in rare cases, can cause HDFN, but this may not be the case in all pregnancies. ${ }^{11}$ 
A rare case of haemolytic disease of newborn with Bombay phenotype mother was reported. ${ }^{24}$ A clinically significant hemolysis can occur in a baby with the Bombay phenotype in the mother. ${ }^{24}$ Despite the high titer of IgG anti $\mathrm{H}$ antibodies (640) babies had escaped HDN. ${ }^{9}$ The relative mildness of the disease could be due to the weak expression of these carbohydrate antigens on RBCs in utero and in neonates or due to the predominant immunoglobulin class which is IgM which does not cross the placenta. ${ }^{9}$

\section{CONCLUSION}

The consequences of mismatched blood transfusion due to errors in cross matching and the difficulty of procuring rare Bombay phenotype blood in emergency situation have been discussed. In obstetric practice, the implications of Bombay phenotype in the causation of HDFN should be kept in mind. In the situation of non availability of Bombay blood group, autologous blood transfusion and cryo preservation need to be considered.

\section{ACKNOWLEDGMENTS}

We wish to express our thanks to the doctor from Care hospital Nampally, Hyderabad, the blood bank officer, who called and informed that it could be Bombay phenotype, which she confirmed after some time.

Dr. Dasari Prasada Rao, the then, director of Nizams institute of medical sciences, whose cooperation was helpful in managing the case at Nizams (NIMS).

\section{Funding: No funding sources}

Conflict of interest: None declared

Ethical approval: Not required

\section{REFERENCES}

1. Bhende YM, Deshpande CK, Bhatia HM, Sanger R, Race RR, Morgan WTJ, et al. A new blood group character related to the ABO system. Lancet. 1952;1(6714):903-4.

2. Oriol R, Candelier JJ, Mollicone R. Molecular genetics of H. Vox Sanguinis. 2000;78(2):105-8.

3. Koda Y, Soejima M, Johnson DH, Smart E, Kimura $\mathrm{H}$. Missense mutation of FUTI and detection of FUT2 are responsible for Indian Bombay Phenotype of ABO blood group system. Biochem Biophys Res Commun. 1997;238(1):21-5.

4. Fernandez-Mateos P, Cailleau A, Henry S, Costache M, Elmgren A, Svensson L, et al. Point mutations and deletion responsible for the Bombay $\mathrm{H}$ null and the Reunion $\mathrm{H}$ weak blood groups. Vox Sang. 1998;75(1):37-46.

5. Bhatia HMSM. Incidence of 'Bombay' (Oh) phenotype and weaker variants of A and B antigen in Bombay (India). Vox Sang. 1974;27:524-32.
6. Balgir RS, Sharma JC. 1988. Genetic markers in the Hindu and Muslim Gujjars of North-western India. Am J Phys Anthropol. 1988;75(3):391-403.

7. Jain A, Kumawat V, Patil SS, Kumar P, Marwaha N, Sharma RR. Significance of serological monitoring in a Bombay Rh (D) negative phenotype pregnant woman: A case report. Transfus Apher Sci. 2012;47(3):251-2.

8. Deo N, Odejinmi F, Dawlatly B, Khan A. Bombay blood group and pregnancy: a rare clinical scenario. $\mathrm{J}$ Obstet Gynaecol. 2005;25(4):398-9.

9. Bhattacharya S, Makar Y, Laycock RA, Gooch A, Poole J, Hadley A. Outcome of consecutive pregnancies in a patient with bombay $(\mathrm{OH})$ blood group. Transfus Med. 2002;12(6):379-82.

10. Ekanem E, Poozhikalayil S, Sinha A. The Bombay blood group: how rare is it? A case report and a review of the literature. J Adv Medic Med Res. 2020;32(7):24-9.

11. Bullock T, Win N, Jackson B, Sivarajan S, Penny J, Mir N. Bombay phenotype (Oh) and high-titer anti-H in pregnancy: two case reports and a review of the literature. Transfusion. 2018;58(12):2766-72.

12. Nikam V, Kashid V, Khapare J. Bombay blood group: an overview. Inventi Rapid: Pharm Pract. 2017;3:1-2.

13. Davey RJ, Tourault MA Holland PV. The clinical significance of antiH in an individual with the $\mathrm{Oh}$ (Bombay) phenotype. Transfusion. 1978;18(6):73842.

14. Toedt ME. Feasibility of autologous blood donation in patients with placenta previa. J Fam Pract. 1999;48(3):219-21.

15. Paudyal P, Gurung G, Adhikari A, Maskey S, Baral J. Elderly gravida with Bombay blood group and placenta previa managed with autologous blood transfusion. Hindawi Case Rep Obstetr Gynecol. 2020.

16. Dinsmoor MJ, Hogg BB. Autologous blood donation with placenta previa: is it feasible? Am J Perinatol. 1995;12(6):382-4.

17. Yamada T, Mori H, Ueki M. Autologous blood transfusion in patients with placenta previa. Acta Obstetricia et Gynecologica Scandinavica. 2005;84(3):255-9.

18. Simon TL, McCullough J, Snyder EL, Solheim BG, Strauss RG. Rossi's principles of transfusion medicine. 5th ed. West Sussex: Wiley-Blackwell Publishing Ltd; 2016: 161.

19. Joshi SR, Vasantha K. A profile of rare bloods in India and its impact in blood transfusion service. Asian $\mathbf{J}$ Transfus Sci. 2012;6(1):42-3.

20. Lin-Chu M, Broadberry RE, Tsai SJ, Chiou PW. The para-Bombay phenotype in Chinese persons. Transfusion. 1987;27(5):388-90.

21. Balgir RS. Detection of a rare blood group, "Bombay (Oh) phenotype" among the Kutia Kondh primitive tribe of Orissa, India. Int $\mathbf{J}$ Hum Genet. 2005;5(3):193-8. 
22. Sathe M, Vasantha K, Mhaisalkar P, Gorakshakar A. Distribution of Bombay (Oh) phenotypes in India. J Indian Anthrop Soc. 1988;23:277-80.

23. Saradabai K, and Sujatha R. A case of antepartum hemorrhage with Bombay blood group. Int J All Med Sci Clinic Res. 2015;3(2):90-2.
24. Shastry S Lewis LE, Bhat SS. A rare case of haemolytic disease of newborn with Bombay phenotype mother. Asian J Transfus Sci. 2013;7(2):141-3.

Cite this article as: Devabhaktuni $\mathrm{P}$, Ponnuru M, Kalattoor VR, Palakodeti N. Bombay phenotype Oh blood group: two case reports. Acute puerperal uterine inversion and term pregnancy in labour. Int $\mathbf{J}$ Reprod Contracept Obstet Gynecol 2021;10:2878-83. 